\title{
A Concurrent Optimization Model for Supplier Selection with Fuzzy Quality Loss
}

\author{
Cucuk Nur Rosyidi (iD, Rina Murtisari (D), Wakhid Ahmad Jauhari \\ Industrial Engineering Department, Universitas Sebelas Maret Surakarta (Indonesia) \\ cucuk@uns.ac.id, rinamurtisari@,gmail.com,wakbidjaubari@gmail.com
}

Received: March 2013

Accepted: February 2017

\section{Abstract:}

Purpose: The purpose of this research is to develop a concurrent supplier selection model to minimize the purchasing cost and fuzzy quality loss considering process capability and assembled product specification.

Design/methodology/approach: This research integrates fuzzy quality loss in the model to concurrently solve the decision making in detailed design stage and manufacturing stage.

Findings: The resulted model can be used to concurrently select the optimal supplier and determine the tolerance of the components. The model balances the purchasing cost and fuzzy quality loss.

Originality/value: An assembled product consists of many components which must be purchased from the suppliers. Fuzzy quality loss is integrated in the supplier selection model to allow the vagueness in final assembly by grouping the assembly into several grades according to the resulted assembly tolerance.

Keywords: supplier selection, optimization, purchasing cost, tolerance, fuzzy quality loss 


\section{Introduction}

An assembled product may consist of several components. Recently, more and more manufacturing companies start to purchase components manufactured by suppliers instead of producing all components by themselves (Xi \& Qin, 2013). The concept of outsourcing is based on the idea that companies should focus their effort to their core competence (Teeravaraprug, 2008). This concept provides many benefits to a company such as reducing production cost, doubling before tax income, improving company's performance, and helping companies for being more focus on their core business (Barthelemy, 2003). The main problem related to outsourcing is how to select suppliers and then determine the component types and quantities that must be allocated to the selected suppliers. Hence supplier selection is complex, difficult, and time consuming since it is strategic and usually involves multi criteria decision making. Weber, Current and Desai (2000) pointed that the difficulties in supplier selection have three reasons: a large number of supplier to select, no single best supplier that offers the best performance in all criteria, and suplliers might change their offers/performance on important criteria.

The quality and variability of components from suppliers are the major concerns of the company since they will affect the quality of the assembled product. The company must focus to a subset of product quality characteristics which known as key characteristics (Rosyidi, Irianto \& Toha, 2009). Hence key characteristics deal with dimensions, features or processes that will significantly affect final cost, performance, or safety of the product. Component tolerances on those key characteristics will affect the quality of a product in term of variations once the components have been assembled. Taguchi quality loss function is widely applied to measure the quality of product. However, the loss function could not be applied in a product with several qualitative grades. Cao, Mao, Ching and Yang (2009) developed a fuzzy quality loss to accommodate the fuzzy and uncertainty in product quality. The aim of this research is to develop a concurrent supplier selection model to minimize the purchasing cost and fuzzy quality loss considering process capability and assembled product specification. Hence we address the problem of supplier selection in a manufacturing company which purchases all of the needed components for assembly from its suppliers. The rest of this paper has the following structure. In Section 2, we briefly review the related literature. The concept of fuzzy quality loss is briefly explained in Section 3. Model development and Numerical example and analysis are given in Section 4 and 5, respectively. The conclusions and future research directions are drawn in the last section. 


\section{Literature Review}

Product quality is a critical concern for most manufacturers and the need for high-quality suppliers has always been an important issue for many manufacturing organizations (Pi \& Low, 2006). Beside quality, purchasing price of components from suppliers is a widely used factor in supplier selection. Linn, Tsung and Ellis (2006) conducted a research in supplier selection using process capability and price analysis. They proposed a methodology using a chart which partitioned the suppliers into several zones according to their quality performances and price levels. Ghorbeni, Bahrami and Arabzad (2012) proposed an integrated model for supplier selection using Shannon Enthropy and SWOT and the order allocation was done using linear programming. Their research included quality and price as the criteria in supplier selection which are assessed qualitatively by the decision maker.

There are two kinds of quality costs that must be considered by a company, i.e. internal and external. Internal quality cost consists of appraisal cost and the cost of rework and scrap. External quality cost measures the loss to society in using a product. Taguchi quality loss is the most widely used function to measure the external quality cost. In Taguchi quality loss, the loss is measured by deviation of mean performance from its target value and the variance of performance level. Using the quality loss, a product still contains losses even its performance is inside the specification limits. Pi and Low (2006) used Taguchi loss function and analytical hierarchy process (AHP) in supplier selection. Taguchi loss function was used to measure the loss in the criteria (quality, on-time delivery, price, and service), while AHP was used to determine the weight of each criteria. Nukala and Gupta (2007) developed a multi-objective optimization model for suppliers selection. The research used Taguchi loss function to measure the quality as one of the criteria in selecting the suppliers. Teeravaraprug (2008) developed an optimization model for outsourcing and supplier selection based on Taguchi loss function. The research used the Taguchi loss function to measure the losses due to poor quality, speed, dependability, and flexibility.

The decision making in engineering problems are often made under uncertainty situations due to the limited data and information (Guneri \& Kuzu, 2009). According to Youn (2005), all engineering uncertainties can be categorized as aleatory and epistemic uncertainty. The former is uncertainty with sufficient statistical information while the later is uncertainty with lack of statistical information. Fuzzy is a concept which can be used to alleviate the epistemic uncertainty and has been applied in many engineering problems. Fuzzy concept was firstly introduced by Zadeh (1965) to deal with the uncertainty and vagueness problems. It also takes into account the human subjectivity in decision making due to linguistic variables which allows precise modeling of impricise statements (Kahraman, Ertay \& Büyüközkan, 2004). There are many research have been conducted in supplier selection to deal with fuzzy environment. For example, Bayrak, Celebi and Taskin (2007) proposed a fuzzy preference index to select 
the best supplier. Guneri and Kuzu (2009) gave a case study in supplier selection using fuzzy approach in just in time environment.

Several research proposed the application of fuzzy in quality design and analysis. Monfared and Dadashian (2005) proposed a fuzzy method in the assessment of quality and applied the results to a textile company. Hsieh (2007) proposed the application of fuzzy to determine the quality loss in parameter design optimization using Taguchi method to improve the quality of qualitative response. Stella and Alena (2012) developed an application of fuzzy principles in evaluating quality of manufacturing process using Matlab. The fuzzy is used to represent the uncertainty in process capability and simulation is conducted to determine the quality of the final product. Xi and Qin (2013) proposed a product quality evaluation system based on AHP fuzzy comprehensive evaluation.

Cao, Mao, Yang, Wu and Wu (2006) and Cao et al. (2009) proposed a robust optimization model to determine the optimal tolerance of an assembly to minimize manufacturing cost and fuzzy quality loss. Using fuzzy quality loss, the products are grouped into several grades in which each grade is determined qualitatively. Hence the assembled product not only contains good or poor quality (classical set theory) but also contains several quality levels that can be determined by fuzzy theory. Chen, Tzeng, Hsu and Chen (2010) proposed the combination of Taguchi method, principal component analysis, and fuzzy logic in the tolerance design of a dual purpose six-bar mechanism. The fuzzy logic in that research is used to derive the multiple performance index from the result of experiment.

All the above research considered suppliers selection and tolerance design as separate decision making problem. The introduction of concurrent engineering has shifted the paradigm from serial product development to simultaneous product development. In the later approach, decision making is made simultaneously by considering many aspects of engineering, productions and supply chain in early product design and development stages. Guneri and Kuzu (2009) also pointed that supply chain includes all activities that perform the functions of product design and development and procurement. An important decision making in product design and development, especially in detail design phase is set the product tolerance and assign the tolerance to its components. Hence in this research, the decision about tolerance design is conducted simultaneously with suppliers selection. The fuzzy quality loss is introduced in the model to accommodate the vagueness and uncertainty in assembly due to the limited information about its quality. 


\section{Fuzzy Quality Loss}

Fuzzy theory is an expansion of the traditional set theory (Hsieh, 2007). In traditional set theory, an object is classified into crisp set. The membership function of a crisp set function only has two values, i.e. 0 or 1. According to Zadeh (1965), fuzzy theory is applied to the classes of objects which do not have precisely defined criteria of membership. Further, it is explained that a fuzzy set A in X is characterized by a membership function which associates with each point in $\mathrm{X}$ a real number in the interval $[0,1]$. Each real number represents the grade of membership of $\mathrm{x}$ in A. Hence, the nearer the real number to unity, the higher the grade of the membership of $\mathrm{x}$ in $\mathrm{A}$.

The operation of fuzzy sets is defined using a subject function $(\mu)$. It is the crucial component of a fuzzy set (Zimmermann, 1991). For more detailed concept about fuzzy set, please refer to Zadeh (1965) which is also briefly explained in Seyed-Hosseini and Damghani (2009). In product quality sense, the subject function can be determined using engineering knowledge and experience (Hsieh, 2007). Figure 1 shows the difference between the classical set and fuzzy set in quality concept. In that figure, $T$ refers to tolerance of a component or assembly. A fuzzy set $\tilde{A}$ in $Y$ is a set of ordered pairs, i.e.

$$
\widetilde{A}=\left\{\left(y, \mu_{\tilde{A}}(y)\right) \mid y \in Y\right\}
$$

where $\mu_{\tilde{A}}(y)$ is called the membership function of $y$ in $\tilde{A}$ and $Y$ is a collection of objects denoted by $y . \tilde{A}$ is a nonfuzzy set if $\mu_{\hat{A}}(y)$ contains only the values of 0 or 1 , in which 0 indicates poor quality and 1 for good quality. However, if $\mu_{\tilde{A}}(y)$ contains several values between 0 and $1, \tilde{A}$ is a fuzzy set. The membership function can be transformed into the linguistic values. Linguistic variables are variables whose values are not numbers but words or sentences in a natural or artificial language, such as very good, good, average, and poor. Linguistic values are used since linguistic characterizations are less spesific than the numerical values.

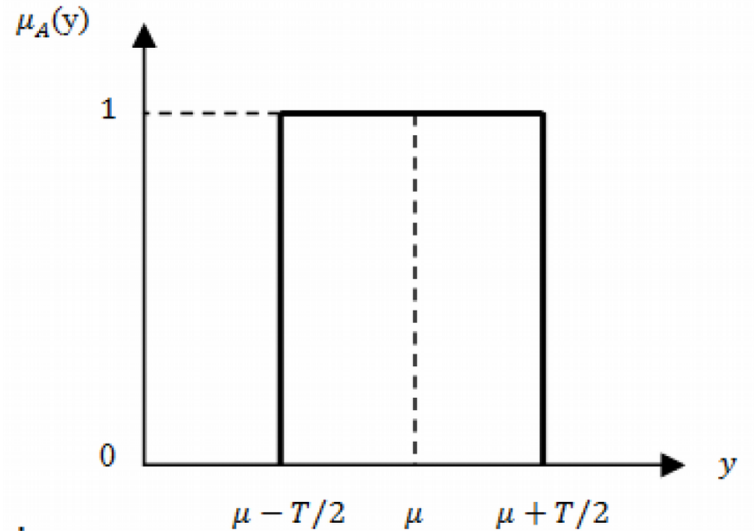

(a) Classical set

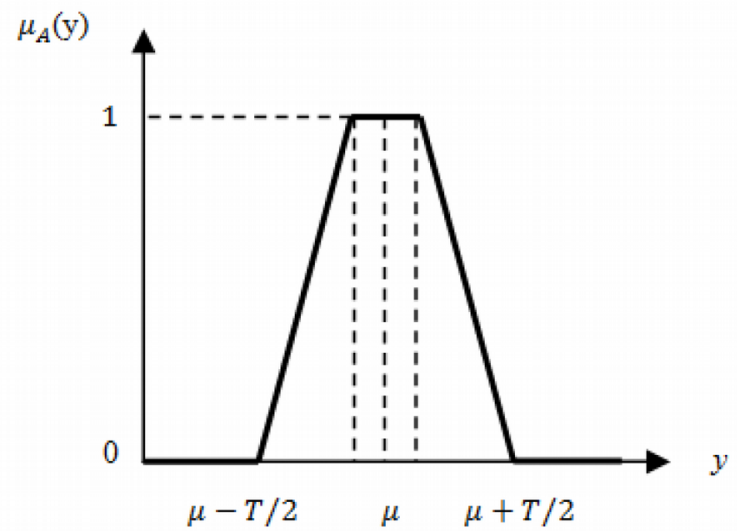

(b) Fuzzy set

Figure 1. The difference between the classical set and fuzzy set 


\section{Model Development}

\subsection{Assumptions}

1. We assume that each component can be supplied by exactly one supplier.

2. The component key characteristic is normally distributed with mean $\mu$ and standard deviation $\sigma$.

3. The manufacturing company faces uncertainty in the quality of assembly due to the limited information about the quality of the components.

\subsection{Variables and Notations}

The following variables and notations are used in model development:

$\tilde{A}_{g}:$ quality grade in fuzzy quality loss

$c_{i j}$ : price of component $i$ from supplier $j$

$c_{p k}:$ process capability index

$f(y)$ : probability density function of normal distribution

$L_{g}$ : respected quality loss of quality grade $g$ in fuzzy quality loss

Q: expected fuzzy quality loss

$R_{g}$ : normalized expected probability of quality grade $g$ in fuzzy quality loss

$t_{i}$ : tolerance of component $i$

$x_{i j}$ : binary decision variable of component $i$ from supplier $j$

$\mu_{A g}(y)$ : fuzzy membership function of quality characteristic $y$ for quality grade $g$

$\sigma_{A s m}:$ assembly standard deviation

$\frac{\partial f}{\partial X_{i}}$ : partial derivative of functional dimension $f$ towards component $i$ 


\subsection{Model Statement and Description}

In this research, we consider a manufacturing company that meet the demand by outsource all of the components to suppliers. Each supplier can supply more than one type of component and each type of component can only be supplied by one supplier. Each supplier offers a price according to the corresponding component tolerance. The objective of the proposed model is to minimize the purchasing cost and fuzzy quality loss. In this research, the objective function of the model can be expressed as in Equation (2). We substitute the Taguchi quality loss in the research of Feng, Wang and Wang (2001) by fuzzy quality loss. In that equation, the value of the binary decision variable is 1 if component $i$ is supplied by supplier $j$ and 0 otherwise. The fuzzy quality loss can be expressed as in Equation (3) which is resulted from the multiplication of the normalized expected probability of the quality grade $g$ and the respected quality loss at each grade $\left(L_{g}\right)$. The quality loss at each grade is determined using the engineering knowledge and experience. The fuzzy quality loss equation is taken from Cao et al. (2009).

$$
\begin{gathered}
\operatorname{Min} y\left(x_{i j}\right)=\sum_{i=1}^{I} \sum_{j=1}^{J}\left(c_{i j} x_{i j}\right)+Q\left(x_{i j}\right) \\
Q=\sum_{g=1}^{G} R_{g} L_{g}
\end{gathered}
$$

The normalized expected probability can be expressed as in Equation (4) (Cao et al., 2009). It represents the proportion of resulted assembly at each quality grade.

$$
R_{g}=\frac{r_{g}}{\sum_{p=1}^{P} r_{p}}
$$

The formulae of $r_{g}$ can be shown in Equation (5) (Cao et al., 2009).

$$
r_{g}=\int_{-\infty}^{\infty} \mu_{A g}(y) f(y) d y
$$

In Equation (5), the density function of the normal probability distribution of quality characteristic $y$ is expressed in Equation (6).

$$
f(y)=\frac{1}{\sigma_{a s m} \sqrt{2 \pi}} e^{-\frac{1}{2}\left(\frac{y-\mu}{\sigma_{a s m}}\right)^{2}}
$$

Note that the standard deviation of the assembly in Equation (6) $\left(\sigma_{A s m}\right)$ equals to the cumulative tolerances of its components. Since we use statistical tolerance, the expression for the assembly standard deviation can be shown in Equation (7).

$$
\sigma_{a s m}=\frac{1}{3 C_{p k}} \sqrt{\sum_{i=1}^{l} t_{i}^{2}}
$$


In this research, we consider the tolerance of the assembled product, the number of selected supplier which is only one for each component, and binary variable which is used to represent the decision variables. The tolerance specification of the assembled product must be considered since it is necessary to ensure the quality of the product. Hence the accumulation of component's tolerance must not exceed the assembly tolerance. The constraint is shown in Equation (8). In the equation, $T_{k}$ denotes the $k$-th assembled tolerance and $\frac{\partial f}{\partial X_{i}}$ is the partial derivative of the functional dimension to component $i$. The number of selected supplier can be expressed in Equation (9) which is only one supplier will be selected for each component.

$$
\begin{gathered}
\sum_{i=1}^{I_{k}} \sum_{j=1}^{J_{i}}\left(\left(\frac{\partial f}{\partial X_{i}}\right)^{2}\left(\frac{t_{i j}}{C_{p k}}\right)^{2} x_{i j}\right) \leq\left(\frac{T_{k}}{c_{p}}\right)^{2} \forall k \\
\sum_{j=1}^{J} x_{i j}=1
\end{gathered}
$$

Binary variable is used to represent the decision variable as in Equation (10). The value of $x_{i j}$ is 1 if supplier $j$ is selected to provide component $i$ and 0 otherwise.

$$
x_{i j}=[0,1] \forall i, j
$$

\section{Numerical Example and Analysis}

A numerical example is given to illustrate the proposed model using a product which consists of three components as shown in Figure 2. Consider the dimensions of $x_{1}, x_{2}$, and $x_{3}$ to be $80 \mathrm{~mm}, 42 \mathrm{~mm}$ and $38 \mathrm{~mm}$, respectively. Parameter data are obtained from Cao et al. (2009). The gap $x_{0}$ is required to be $0.2 \mathrm{~mm}$ to maintain the normal performance. The company has limited information concerning the quality of the resulted assembly. The fuzzy approach has a benefit in this situation comparing the crisp set in which the quality of the resulted assembly can be defined semantically and then the fuzzy membership function must also be defined for each quality grade. The membership functions for the three grades that can be determined using engineering knowledge and experience. 


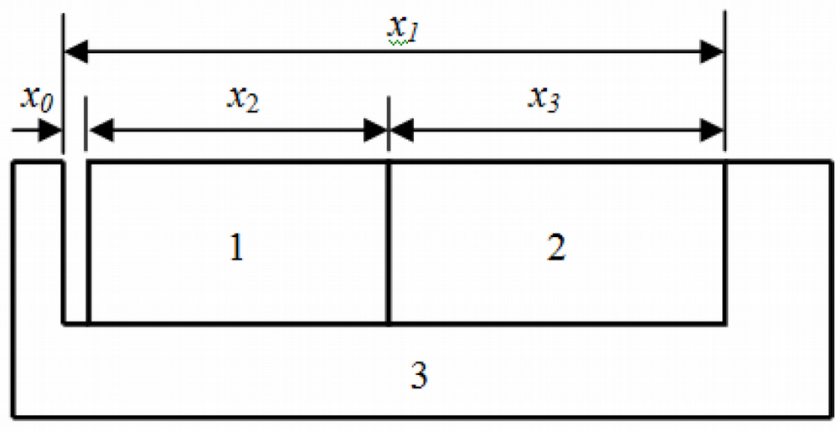

Figure 2. The assembly drawing

Fuzzy quality sets and quality loss for each quality level must be defined first. In the numerical example, we assume there are three quality grades (good, general, and poor). Each quality grade has different quality loss, as shown in Table 1 (Cao et al., 2009). For good quality grade, the corresponding quality loss is zero since there is no loss for a product with good quality. For general and poor quality grades, the corresponding quality losses are IDR 25,000 and IDR 40,000 respectively.

\begin{tabular}{|c|c|c|c|}
\hline Quality level, $\boldsymbol{i}$ & Fuzzy quality sets, $\tilde{A}$ & Quality loss, $\boldsymbol{L}$ & Quality grade \\
\hline 1 & $\tilde{A_{1}}$ & $L_{1}=0$ & Good quality \\
\hline 2 & $\tilde{A_{2}}$ & $L_{2}=25,000$ & General quality \\
\hline 3 & $\tilde{A_{3}}$ & $L_{3}=40,000$ & Poor quality \\
\hline
\end{tabular}

Table 1. Fuzzy quality sets and quality loss

The trapezoidal-type fuzzy membership functions are used for good and poor quality grade, while triangular-type is used for general quality. The fuzzy membership functions for each quality grade are listed in Equations (11), (12), and (13) for good, general, and poor respectively (Cao et al., 2009). With trapezoidal-type membership function, an assembly is considered to be in good grade if the resulted assembly key characteristic is $0.12 \leq \mathrm{y} \leq 0.28 \mathrm{~mm}$. The key characteristic is considered in the best good quality when $0.18 \leq \mathrm{y} \leq 0.22 \mathrm{~mm}$. The lowest good grade is considered when the key characteristic is either less than 0.12 or more than $0.28 \mathrm{~mm}$. The expected fuzzy membership functions can be determined by substituting Equations (11), (12), and (13) into Equation (5).

$$
\mu_{A 1}(y)=\left\{\begin{array}{c}
0, y<0.12 \\
(50 y-6) / 3,0.12 \leq y<0.18 \\
1,0.18 \leq y \leq 0.22 \\
(14-50 y) / 3,0.22<y \leq 0.28 \\
0, y>0.28
\end{array}\right.
$$




$$
\begin{gathered}
\mu_{A 2}(\mathrm{y})=\left\{\begin{array}{c}
0, y<0.08 \\
(25 \mathrm{y}-2) / 3,0.08 \leq y<0.2 \\
(8-25 \mathrm{y}) / 3,0.2 \leq y<0.32 \\
0, \mathrm{y}>0.32
\end{array}\right. \\
\mu_{A 3}(\mathrm{y})=\left\{\begin{array}{c}
1, y<0.08 \\
1,8-10 y, 0.08 \leq y<0.18 \\
0,0.18 \leq \mathrm{y}<0.22 \\
10 y-2,2,0.22 \leq \mathrm{y}<0,32 \\
1, y>0.32
\end{array}\right.
\end{gathered}
$$

Different suppliers offer different prices with the coresponding variability of their products. Purchase price and tolerance data of each component from different suppliers are shown in Table 2.

\begin{tabular}{|c|r|r|r|r|r|r|}
\hline \multirow{2}{*}{ Supplier } & \multicolumn{2}{|c|}{ Component 1 } & \multicolumn{2}{c|}{ Component 2 } & \multicolumn{2}{c|}{ Component 3 } \\
\cline { 2 - 7 } & \multicolumn{1}{|c|}{$\begin{array}{c}\text { Tolerance } \\
(\mathrm{mm})\end{array}$} & Price (IDR) & $\begin{array}{c}\text { Tolerance } \\
(\mathrm{mm})\end{array}$ & Price (IDR) & $\begin{array}{c}\text { Tolerance } \\
(\mathrm{mm})\end{array}$ & Price (IDR) \\
\hline P1 & 0.08 & 17,800 & 0.1 & 17,000 & 0.15 & 15,000 \\
\hline P2 & 0.1 & 15,575 & 0.12 & 16,200 & 0.05 & 20,000 \\
\hline P3 & 0.12 & 13,350 & 0.06 & 18,500 & 0.08 & 17,000 \\
\hline
\end{tabular}

Table 2. Price and tolerance data for each component for each supplier

We assume that each supplier has a process capability index of $\mathrm{Cpk}=2$ for each component. The optimization result shows that Supplier 3 is selected to supply Components 1 and 3, while Component 2 is supplied by Supplier 2. Supplier 3 and Supplier 2 were selected to supply components 1 and 2 since they offered the components with lowest price. For component 3, instead of Supplier 1 which offering the lowest price, the model selected Supplier 3. This selection is obvious since if Supplier 1 was selected, then the decision will exceed the quality constraints (Equation 8). The purchasing cost and fuzzy quality loss for the numerical example are IDR. 46,550 and IDR. 13,748 respectively, resulting in a total cost of IDR. 60,298. The proportion of each quality grade and the respected fuzzy quality loss are shown in Table 3. From the table we can see that good and general quality grades account for almost $95 \%$ from the total assembly.

\begin{tabular}{|l|r|r|}
\hline $\boldsymbol{R}_{\boldsymbol{g}}$ & The Normalized Expected Probability & \multicolumn{2}{|c|}{ Fuzzy Quality Loss (IDR) } \\
\hline$R_{1}$ & 0.4844 & 0 \\
\hline$R_{2}$ & 0.4584 & 11,460 \\
\hline$R_{3}$ & 0.0572 & 2,288 \\
\hline
\end{tabular}

Table 3. Fuzzy quality loss for each quality level 


\section{Conclusions}

A concurrent optimization model for supplier selection with fuzzy quality loss is proposed to achieve the balance between purchasing cost and quality loss. The main contribution of this research was to integrate fuzzy quality loss into supplier selection model. This model can be used to effectively minimize the purchasing cost and fuzzy quality loss and it can be used to aid a decision maker in making decisions concerning supplier selection and tolerance allocation. This research applied a fuzzy quality loss to measure the quality loss for the assembly product with limited quality information. Hence the quality must be defined semantically and the membership function for each grade must be defined using engineering knowledge and experience. Future research is directed to include the component's allocation decision to the selected supplier based on fuzzy quality loss.

\section{References}

Barthelemy, J. (2003). The Seven Deadly Sins of Outsourcing. Academy Of Management Executive, 17(2), 87-98. https://doi.org/10.5465/AME.2003.10025203

Bayrak, M.Y., Celebi, N., \& Taskin, H. (2007). A Fuzzy Approach for Supplier Selection. Production Planning and Control, 18(1), 54-63. https://doi.org/10.1080/09537280600940713

Cao, Y., Mao, J., Yang, J., Wu, Z., \& Wu, L. (2006). A Robust Tolerance Design Method Based on Fuzzy Quality Loss. Frontier of Machanical Engineering China, 1, 101-105. https://doi.org/10.1007/s11465-005-0010-y

Cao, Y., Mao, J., Ching, H., \& Yang, J. (2009). A Robust Tolerance Optimization Method Based on Fuzzy Quality Loss. Proceedings of the Institution of Mechanical Engineers, Part C: Journal of Mechanical Engineering Science, 223, 2647-2653. https://doi.org/10.1243/09544062jmes1451

Chen, F., Tzeng, Y., Hsu, M., \& Chen, W. (2010). Combining Taguchi Method, Principal Component Analysis and Fuzzy Logic to The Tolerance Design of a Dual-Purpose Six Bar Mechanism. Transactions of the Canadian Society for Mechanical Engineering, 34(2).

Feng, C.X., Wang, J., \& Wang, J.S. (2001). An Optimization Model for Concurrent Selection of Tolerances and Supplier. Computers and Industrial Engineering, 40, 15-33. https://doi.org/10.1016/S0360-8352(00)00047-4

Ghorbeni, M., Bahrami, M., \& Arabzad, S.M. (2012). Integrated Model for Supplier Selection and Order Allocation; Using Shannon Enthropy, SWOT, and Linear Programming. Procedia Social and Behavioral Sciences, 14, 521-527. https://doi.org/10.1016/j.sbspro.2012.04.064 
Guneri, A.F., \& Kuzu, A. (2009). Supplier Selection by Using A Fuzzy Approach in Just-In-Time: A Case Study. International Journal of Computer Integrated Manufacturing, 22(8), 774-783.

https://doi.org/10.1080/09511920902741075

Hsieh, K.L. (2007). Applying Fuzzy Set Approach into Achieving Quality Improvement for Qualitative Quality Response. Proceedings of the 2007 WSEAS International Conference on Computer Engineering and Applications, Gold Coast, Australia.

Kahraman, C., Ertay, T., \& Büyüközkan, G. (2004). A Fuzzy Optimization Model for QFD Planning Process Using Analytic Network Approach. European Journal of Operational Research.

Linn, R.J., Tsung, F., \& Ellis, L.W.C. (2006). Supplier Selection Based on Process Capability and Price Analysis. Quality Engineering, 18, 123-129. https://doi.org/10.1080/08982110600567475

Monfared, M.A.S., \& Dadashian, F. (2005). Design of A New Quality Assessment System Using Fuzzy Taguchi Functions. Proceedings of the $17^{\text {th }}$ IMACS Worldd Congress, Paris.

Nukala, S., \& Gupta, S.M. (2007). A Fuzzy Mathematical Programming Approach for Supplier Selection in a Closed-Loop Supply Chain Network. Proceedings of the 2007 POM Dallas Meeting.

Pi, W., \& Low, C. (2006). Supplier Evaluation and Selection via Taguchi Loss Functions and an AHP. International Journal of Advanced Manufacturing Technology, 27, 625-630. https://doi.org/10.1007/s00170-004$2227-z$

Rosyidi, C.N., Irianto, D., \& Toha, I.S. (2009). Prioritizing Key Characteristics. Journal of Advanced Manufacturing Systems, 8(1), 57-70. https://doi.org/10.1142/S0219686709001675

Seyed-Hosseini, S-M., \& Damghani, K.K. (2009). Fuzzy Containers Allocation Problem in Maritime Terminal. Journal of Industrial Engineering and Management, 2(2), 323-336. https://doi.org/10.3926/jiem.2009.v2n2.p323-336

Stella, H., \& Alena, V. (2012). Application of Fuzzy Principles in Evaluating Quality of Manufacturing Process. WSEAS Transactions on Power Systems, 2(7).

Teeravaraprug, J. (2008). Outsourcing and Vendor Selection Model Based On Taguchi Loss Function. Songklanakarin Journal of Science and Technology, 30(4), 523-530.

Weber, C.A., Current, J.R., \& Desai, A. (2000). Vendor: A Structured Approach to Vendor Selection and Negotiation. Journal of Business Logistics, 21(1),135-167. 
Xi, X. \& Qin, Q. (2013). Product Quality Evaluation System Based on AHP Fuzzy Comprehensive Evaluation. Journal of Industrial Engineering and Management, 6(1), 356-366. https://doi.org/10.3926/jiem.685

Youn, B.D. (2005). Integrated Framework for Design Optimization Under Aleatory And/Or Epistemic Uuncertainties Using Adaptive-Loop Method. Proceedings of DETC '05, California.

Zadeh, L.A. (1965). Fuzzy Sets. Information and Control, 8, 338-353. https://doi.org/10.1016/S00199958(65)90241-X

Zimmermann, H.J. (1991). Fuzay Set Theory and Its Applications (2nd ed.). Kluwer Academic Publishers. https://doi.org/10.1007/978-94-015-7949-0

Journal of Industrial Engineering and Management, 2017 (www.jiem.org)

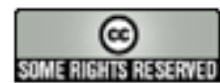

Article's contents are provided on an Attribution-Non Commercial 3.0 Creative commons license. Readers are allowed to copy, distribute and communicate article's contents, provided the author's and Journal of Industrial Engineering and Management's names are included. It must not be used for commercial purposes. To see the complete license contents, please visit http://creativecommons.org/licenses/by-nc/3.0/. 